\title{
Identification and pharmacokinetics of saponins in Rhizoma Anemarrhenae after oral administration to rats by HPLC-Q-TOF/MS and HPLC-MS/MS
}

HAI-QIAO WANG ${ }^{1, a}$

FEN LAN ${ }^{2, a}$

YI-HAN ZHANG

JIN-ER XIA ${ }^{2}$

XIAO-MEI GONG ${ }^{3, *}$

MIN LIU ${ }^{2, *}$

${ }^{1}$ Renji Hospital, School of Medicine

Shanghai Jiaotong University

Shanghai 201112, China

${ }^{2}$ Department of Pharmacy

Shanghai Changhai Hospital, Second

Military Medical University

Shanghai 200433, China

${ }^{3}$ Department of Radiation Oncology Shanghai Pulmonary Hospital, Tongji University, School of Medicine

Shanghai 200433, China
Accepted October 9, 2020

Published online November 9, 2020

\begin{abstract}
Rhizoma Anemarrhenae is a well-known herbal medicine with saponins as its commonly regarded major bioactive components. It is essential to classify the properties of saponins which are associated with their toxicity and efficacy. In this study, 25 compounds were identified by HPLC-Q-TOF/MS in the extract of Rhizoma Anemarrhenae and 8 saponins were detected in rat plasma by HPLC-MS/MS after oral administration of this extract. These were neomangiferin, mangiferin, timosaponin E1, timosaponin E, timosaponin B-II, timosaponin B-III, timosaponin A-III and timosaponin A-I. A sensitive and accurate HPLC-MS/MS method was developed and successfully applied to a pharmacokinetic study of the abovementioned eight saponins after oral administration of the Rhizoma Anemarrhenae extract to rats. The method validation, including specificity, linearity, precision, accuracy, recovery, matrix effect and robustness, met the requirements of the intended use. The pharmacokinetic parameter, $T_{\max }$ value, ranged from 2 to $8 \mathrm{~h}$ for these eight saponins whereas their elimination half-life $\left(t_{1 / 2}\right)$ ranged from 4.06 to $9.77 \mathrm{~h}$, indicating slow excretion. The plasma concentrations of these eight saponins were all very low, indicating a relatively low oral bioavailability. All these results provide support for further clinical studies.
\end{abstract}

Keywords: Rhizoma Anemarrhenae, saponin, identification, pharmacokinetics, HPLC-Q-TOF/MS, HPLC-MS/MS

Rhizoma Anemarrhenae, the dried rhizome of Anemarrhena asphodeloides, is a well-known traditional herbal medicine in China, Korea, and Japan (1). As a typical herbal medicine, Rhizoma Anemarrhenae has been extensively used for the treatment of inflammatory and other diseases, including cough, fever, allergies, Alzheimer's disease and diabetes (2-5). Modern pharmacological research has also revealed its antidepressant, antidiabetic, anti-inflammatory, antiplatelet aggregation, and antipyretic effects $(6,7)$. Previous studies have shown that Rhizoma Anemarrhenae contains steroidal saponins, flavonoids,

\footnotetext{
*Correspondence; e-mail: gongxiaomei1981@163.com; lm_yaofen2003@163.com

${ }^{a}$ H.-Q. Wang and F. Lan equally contributed to this work.
} 
H.-Q. Wang et al.: Identification and pharmacokinetics of saponins in Rhizoma Anemarrhenae after oral administration to rats by HPLC-Q-TOF/MS and HPLC-MS/MS, Acta Pharm. 71 (2021) 567-585.

polysaccharides, lignans, etc. $(4,5,8,9)$, among which steroidal saponins are commonly regarded as the major bioactive components (10). These components have been demonstrated various pharmacological properties including blood coagulation (11), attenuation of senile dementia $(12,13)$, tumour progression (1), inflammation $(4,14-17)$, and osteoporosis (18). It is worth noting that over-administering some saponins can also cause cardiovascular disorders and even death (19).

Several previous studies have investigated the pharmacokinetics of timosaponin B-II and timosaponin A-III, two important steroidal saponins in Rhizoma Anemarrhenae, and showed slow absorption and low bioavailability after administration (20,21). However, few systematic studies have addressed the pharmacokinetic characteristics of the total saponins in Rhizoma Anemarrhenae after the administration of its saponin extract (22-24).

The aim of this study was to identify the main saponins in rat plasma after oral administration of Rhizoma Anemarrhenae saponin extract using high-performance liquid chromatography-tandem quadrupole time-of-flight mass spectrometry (HPLC-Q-TOF/MS), and to elucidate their pharmacokinetic characteristics by high-performance liquid chromatography-tandem triple quadrupole mass spectrometry (HPLC-MS/MS). Wang et al. (25) have established this HPLC-TOF/MS method. Here we applied it to the identification of chemical components in Rhizoma Anemarrhenae asphodeloides saponin extract and those absorbed into the blood. Also, here, an HPLC-MS/MS method was developed, validated and applied the first time, for quantitation of 8 saponins in the extract before administration, and afterward for the pharmacokinetic assays.

\section{EXPERIMENTAL}

\section{Chemicals and reagents}

Standards of neomangiferin, mangiferin, timosaponin E1, timosaponin E, timosaponin B-II, timosaponin B-III, timosaponin AIII, timosaponin A-I and the internal standard (IS), carbamazepine, were obtained from the National Institute for the Control of Pharmaceutical and Biological Products (China). Their structures were fully characterized by nuclear magnetic resonance (NMR) spectroscopy and mass spectrometry (MS), and their purities were shown to be over $98.5 \%$.

Acetonitrile and methanol were of HPLC grade and were purchased from Honeywell (USA). HPLC-quality water was purified using a Milli-Q water purification system (Millipore, USA). All other reagents were of analytical grade.

The crude drug Rhizoma Anemarrhenae was purchased from the Shanghai Huayu Medicine Corporation (China) and authenticated by Prof. L. N. Sun, School of Pharmacy, Second Military Medical University, Shanghai, China.

\section{Preparation of Rhizoma Anemarrhenae saponin extract}

The dried crude drug was ground in a laboratory mill. One hundred grams of Rhizoma Anemarrhenae powder was extracted by ultrasound sonication with $500 \mathrm{~mL} 70 \%$ ethanol for $30 \mathrm{~min}$ and then refluxed for $2 \mathrm{~h}$. After vacuum filtration, another $500 \mathrm{~mL} 70 \%$ ethanol was added to filter residue for an additional $2 \mathrm{~h}$ of reflux extraction and filtered again. The 
H.-Q. Wang et al.: Identification and pharmacokinetics of saponins in Rhizoma Anemarrhenae after oral administration to rats by HPLC-Q-TOF/MS and HPLC-MS/MS, Acta Pharm. 71 (2021) 567-585.

filtrates from the two extractions were mixed and concentrated to $100 \mathrm{~mL}$ (equivalent to $1 \mathrm{~g}$ crude herb per $\mathrm{mL}$ ) for intragastric administration.

To identify the chemical components in Rhizoma Anemarrhenae, $1 \mathrm{~mL}$ of the Rhizoma Anemarrhenae saponin extract was diluted with $25 \mathrm{~mL}$ methanol. After $30 \mathrm{~min}$ of ultrasound sonication, the sample was vacuum filtered and the filtrate was used for the identification of chemical components in Rhizoma Anemarrhenae.

\section{Animals}

Male Sprague-Dawley rats aged 8 weeks (220-250 g) were provided by the Experimental Animal Center of the Second Military Medical University (Shanghai, China). SpragueDawley rats were bred in a breeding room at $22 \pm 2{ }^{\circ} \mathrm{C}$ with $50 \pm 10 \%$ relative humidity and a 12-h dark-light cycle. All animal experimental procedures conformed to the European Community Guidelines for Animal Experimentation and Welfare. The animal experimentation studies were approved by the Ethics Committee on Animal Research in Second Military Medical University (Shanghai, China). Before the experiments, the animals underwent 1 week of acclimatization with food and water provided ad libitum and were fasted with free access to water for $12 \mathrm{~h}$ prior to the oral administration. After finishing the animal experiment, the rats were sacrificed by cervical dislocation under anesthesia.

\section{Standard solutions}

Stock solutions. - Standard stock solution for any of the eight saponins was prepared by accurately weighing and dissolving the respective standard and internal standard in acetonitrile at the concentration of $200 \mathrm{\mu g} \mathrm{mL}^{-1}$ for each saponin and $100 \mathrm{ng} \mathrm{mL}^{-1}$ for the IS, and stored at $4{ }^{\circ} \mathrm{C}$.

Calibration standards and quality control samples. - A series of standard solutions was obtained by diluting the abovementioned standard stock solutions with acetonitrile. The calibration standards were prepared by spiking $20 \mu \mathrm{L}$ of standard solutions and $180 \mu \mathrm{L}$ of IS solution into $100 \mu \mathrm{L}$ of blank rat plasma to obtain the concentrations of $2.5-250 \mathrm{ng} \mathrm{mL}^{-1}$ for neomangiferin, mangiferin, timosaponin E1, timosaponin E, timosaponin B-III, timosaponin AIII and timosaponin A-I, and 5-500 $\mathrm{ng} \mathrm{mL}^{-1}$ for timosaponin B-II. The mixture was then centrifuged at $12000 \mathrm{rpm}$ for $10 \mathrm{~min}$. Then the supernatant was transferred into an injection vial and a $2-\mu \mathrm{L}$ aliquot was injected into the HPLC-MS/MS system for analysis.

Quality control (QC) samples were prepared by spiking $20 \mu \mathrm{L}$ of standard solutions and $180 \mu \mathrm{L}$ of IS solution into $100 \mu \mathrm{L}$ of blank rat plasma to obtain three concentrations of 10, 50, $250 \mathrm{ng} \mathrm{mL}^{-1}$ for timosaponin B-II and 5, 25, $100 \mathrm{ng} \mathrm{mL}^{-1}$ for other 7 saponins. The mixture was centrifuged for $10 \mathrm{~min}$ at $12000 \mathrm{rpm}$ and the $2-\mu \mathrm{L}$ aliquot of the supernatant was injected.

\section{HPLC-Q-TOF/MS}

For the identification of chemical compounds in Rhizoma Anemarrhenae extract and in rat plasma, an Agilent 1290 ultra-high-performance liquid chromatography-tandem quad- 
H.-Q. Wang et al.: Identification and pharmacokinetics of saponins in Rhizoma Anemarrhenae after oral administration to rats by HPLC-Q-TOF/MS and HPLC-MS/MS, Acta Pharm. 71 (2021) 567-585.

rupole time-of-flight mass spectrometer (HPLC-Q-TOF/MS, Agilent Technology Co., USA) was used, which consisted of a quaternary pump, an on-line degasser, a well-plate autosampler, a thermostatic column compartment and a 6210 TOF mass spectrometer. The chromatographic separations were performed at $30^{\circ} \mathrm{C}$ on a Waters $X$ bridge $\mathrm{C}_{18}$ column $(3.5 \mu \mathrm{m}$, $3.0 \times 100 \mathrm{~mm}$, Waters, USA). The mobile phase consisted of (A) water/formic acid (100:0.1, $V / V)$ and $(\mathrm{B})$ acetonitrile/formic acid (100:0.1, $V / V)$ with the following gradient elution: $0-3$ min, 18-22 \% B; 3-8 min, 22-25 \% B; 8-10 min, 25-40\% B; and 10-15 min, 40-60 \% B. The flow rate was set at $400 \mu \mathrm{L} \mathrm{min}{ }^{-1}$. The sample injection volume was $2 \mu \mathrm{L}$. The parameters of the ion source were as follows: acquisition mode, positive mode; capillary voltage 3500 $\mathrm{V}$; drying gas $\left(\mathrm{N}_{2}\right)$ temperature $350^{\circ} \mathrm{C}$; drying gas flow rate, $10 \mathrm{~L} \mathrm{~min}^{-1}$; nebulizer gas $\left(\mathrm{N}_{2}\right)$ pressure $241 \mathrm{kPa}$; the fragmentor voltage $180 \mathrm{~V}$ and skimmer voltage $60 \mathrm{~V}$. Mass spectra in the full-scan mode were recorded between $\mathrm{m} / \mathrm{z} 100$ and 1200. Agilent MassHunter B4.0 software was used for the control of equipment, data acquisition and analysis.

\section{HPLC-MS/MS}

For the pharmacokinetic study of eight saponins, an Agilent 1290 high-performance liquid chromatography triple quadrupole mass spectrometer (HPLC-MS/MS) was used, which consisted of a degasser, a G7120A binary pump, a G7167B autosampler and a G7116B thermostated column compartment. An Agilent 6470 triple quadrupole mass spectrometer equipped with standard AJS electrospray ionization (ESI Jet stream - positive ions) was coupled to the HPLC system. Chromatographic separation was performed on the Waters Xbridge $\mathrm{C}_{18}$ column $(3.5 \mathrm{~mm}, 3.0 \times 100 \mathrm{~mm})$ at $30^{\circ} \mathrm{C}$. The mobile phase system was composed of (A) $0.1 \%(V / V)$ aqueous formic acid and (B) acetonitrile. The following gradient elution was used: $0-4 \mathrm{~min}, 5-95 \% \mathrm{~B}$ and $4-8 \mathrm{~min}, 95 \% \mathrm{~B}$. The flow rate was $0.4 \mathrm{~mL} \mathrm{~min}{ }^{-1}$ and the analysis time was $8 \mathrm{~min}$. An aliquot of $2 \mu \mathrm{L}$ of the solution was injected into the HPLC-MS/MS system for analysis. The flow outlet was directed to the mass spectrometer. The mass scan mode was positive dynamic MRM (fragmentor $110 \mathrm{~V}$, skimmer $60 \mathrm{~V}$ ), and each pair of precursor and product transitions of the analytes was auto-optimized by HPLC-MS/MS. The precursor-to-product ion pairs were $m / z 585.1 \rightarrow 303.1$ for neomangiferin, $\mathrm{m} / \mathrm{z} 423.1 \rightarrow 303.1$ for mangiferin, $\mathrm{m} / \mathrm{z} 937.5 \rightarrow 775.5$ for timosaponin $\mathrm{E} 1, \mathrm{~m} / \mathrm{z} 937.5 \rightarrow 775.5$ for timosaponin E, $m / z \quad 921.5 \rightarrow 759.5$ for timosaponin B-II, $m / z \quad 903.5 \rightarrow 741.5$ for timosaponin B-III, $m / z 741.5 \rightarrow 579.5$ for timosaponin A-III, and $m / z 579.5 \rightarrow 417.3$ for timosaponin A-I. The following MS/MS working parameters were used after optimization: drying gas temperature $350{ }^{\circ} \mathrm{C}$, drying gas flow rate $10 \mathrm{~L} \mathrm{~min}^{-1}$, nebulizer gas pressure $275.8 \mathrm{kPa}$, sheath gas temperature $350^{\circ} \mathrm{C}$, sheath gas flow rate $11 \mathrm{~L} \mathrm{~min}^{-1}$ and capillary voltage $3.5 \mathrm{kV}$.

\section{HPLC-MS/MS validation}

Validation of the HPLC-MS/MS method was performed with respect to specificity, accuracy, precision, the limit of detection $(L O D)$, the limit of quantification $(L O Q)$, linearity and range, robustness and stability according to the International Conference on Harmonisation (ICH) guidelines (26).

Method specificity was investigated by comparing eight different rat plasma samples after oral administration of saponin extract, with blank plasma.

For each analyte, the linearity range was tested by spiking the saponin and IS into blank plasma samples in the concentration range of 2.5 to $25 \mathrm{ng} \mathrm{mL}^{-1}$, and five independent runs were conducted. 
H.-Q. Wang et al.: Identification and pharmacokinetics of saponins in Rhizoma Anemarrhenae after oral administration to rats by HPLC-Q-TOF/MS and HPLC-MS/MS, Acta Pharm. 71 (2021) 567-585.

For each saponin, $L O D$ and $L O Q$ were calculated using calibration curve data following the equations: $L O D=3.3 \times \mathrm{SD} /$ slope and $L O Q=10 \times \mathrm{SD} /$ slope, where $\mathrm{SD}$ is the standard deviation of the regression line.

The intra- and inter-day precision and accuracy of the method were determined by using QC samples at low, medium and high concentration for three consecutive days. Rat plasma standard solutions including 8 saponins were used. For each concentration, five replicates were prepared. The concentration of each saponin was calculated by using a calibration curve on the same testing day. The accuracy was evaluated as the mean deviation from the theoretical value and expressed as a percentual relative error.

Three sets of samples (A-C) at low, medium and high concentrations were prepared for the evaluation of extraction recovery (RE) and matrix effect (ME), and each concentration was prepared in five replicates. Set A was prepared by diluting the working standard solutions with methanol, set B was composed of blank plasma and working standard solutions spiked before protein precipitation, in set $C$ the spiking of the working solutions in blank plasma was performed after protein precipitation. RE and ME were evaluated by comparing the ratio of peak area of three sets of samples as follows: RE $(\%)=\mathrm{B} / \mathrm{A} \times 100$ and $\operatorname{ME}(\%)=\mathrm{C} / \mathrm{A} \times 100$, where $\mathrm{A}, \mathrm{B}$ and is the mean peak area ratio of saponin to IS of the respective set. In short, RE of saponins was determined by comparing the peak areas obtained from blank plasma spiked with analytes before the extraction with those from samples to which analytes were added after the extraction, whereas ME was assessed by comparing the blank plasma samples mixed with each saponin after the extraction process with the corresponding standard solution.

Robustness was evaluated by deliberate changes in chromatographic conditions such as the mobile phase flow rate $\left( \pm 0.1 \mathrm{~mL} \mathrm{~min}^{-1}\right)$, column temperature $\left( \pm 2{ }^{\circ} \mathrm{C}\right)$, gas temperature $\left( \pm 10^{\circ} \mathrm{C}\right)$ and drying gas flow rate $\left( \pm 1 \mathrm{~mL} \mathrm{~min}^{-1}\right)$.

Stability was evaluated by analysing three QC samples at a low, medium and high level under different storage conditions. Short-term stability was measured by exposing the QC samples to room temperature for $24 \mathrm{~h}$. Long-term stability was tested at $-40{ }^{\circ} \mathrm{C}$ for 30 days and freeze/thaw stability after three freeze-thaw cycles of the plasma samples.

\section{Plasma samples and pharmacokinetic study}

Six SD rats were intragastrically administered Rhizoma Anemarrhenae saponin extract at a dose equivalent to $10 \mathrm{~g}$ crude drug $\mathrm{kg}^{-1}$ rat. After drug administration, rat blood samples were collected into heparinized tubes via the caudal vein at 1, 2, $4 \mathrm{~h}$ and mixed finally. After centrifugation at $4000 \mathrm{rpm}$ for $10 \mathrm{~min}$, plasma samples were collected and a $100-\mu \mathrm{L}$ aliquot of plasma sample was removed to a 1.5-mL polypropylene tube, $200 \mu \mathrm{L}$ acetonitrile added and vortexed for $30 \mathrm{~s}$. This mixture was centrifuged at $12000 \mathrm{rpm}$ for $10 \mathrm{~min}$. Then, the supernatant was transferred into an injection vial and a $2-\mu \mathrm{L}$ aliquot was injected into the HPLC-Q-TOF/MS for identification of saponins in rat plasma.

Plasma samples for pharmacokinetic analyses were prepared as follows. Six male SD rats were given the saponin extract of Rhizoma Anemarrhenae (equivalent to $3 \mathrm{~g}$ crude drug $\mathrm{kg}^{-1}$ rat) per os. Blood samples $(0.3 \mathrm{~mL})$ were collected through the caudal vein into heparinized tubes, before drug administration (time zero), and at 0.083, 0.25, 0.5, 1, 2, 4, 6, 8, 12, 24, 36 and $48 \mathrm{~h}$ after drug administration. Plasma samples were centrifuged at $4000 \mathrm{rpm}$ for 
H.-Q. Wang et al.: Identification and pharmacokinetics of saponins in Rhizoma Anemarrhenae after oral administration to rats by HPLC-Q-TOF/MS and HPLC-MS/MS, Acta Pharm. 71 (2021) 567-585.

$10 \mathrm{~min}$, then collected and frozen at $-40{ }^{\circ} \mathrm{C}$ until analysis by HPLC-MS/MS. To a $100-\mu \mathrm{L}$ aliquot of plasma sample, $180 \mu \mathrm{L}$ of the IS solution and $20 \mu \mathrm{L}$ acetonitrile were added and vortexed for $30 \mathrm{~s}$ in a 1.5-mL polypropylene tube. The obtained mixture was then centrifuged at $12000 \mathrm{rpm}$ for $10 \mathrm{~min}$. After the supernatant was transferred into an injection vial, a $2-\mu \mathrm{L}$ aliquot was injected into the HPLC-MS/MS system for the determination of eight saponins.

The pharmacokinetic parameters were calculated using DAS version 3.0 (BioGuider Co., China). A non-compartmental model was used to calculate the following parameters: maximum plasma concentration $\left(C_{\max }\right)$ and time to attain $C_{\max }\left(T_{\max }\right)$ were obtained directly from the concentration-time curves. The elimination rate constant $(k)$ was calculated by linear regression of the final linear part of the plasma concentration-time curve. The elimination half-life $\left(t_{1 / 2}\right)$ was calculated as $0.693 / k$. The area under the concentration-time curve $\left(A U C_{0-t}\right)$ was calculated using the linear trapezoidal rule. Mean residence time $(M R T)$ was calculated from the formula $M R T=A U M C_{0-\infty} / A U C_{0-\infty}$, where $A U M C_{0_{-\infty}}$ indicates the area under the first part of the plasma concentration-time curve. All the data are presented as the mean $\pm \mathrm{SD}$.

\section{RESULTS AND DISCUSSION}

\section{Chemical composition of Rhizoma Anemarrhenae saponin extract}

The HPLC-Q-TOF/MS chromatogram of Rhizoma Anemarrhenae saponin extract is shown in Fig. 1. By comparing three batches of raw Rhizoma Anemarrhenae with chemical components reported in the literature (10, 20, 27), 25 common peaks were confirmed (Table I), according to their retention time, accurate molecular mass and molecular formula.

The content of 8 saponins in the Rhizoma Anemarrhenae extract was determined by HPLC-MS/MS: neomangiferin $11.86 \mathrm{mg} \mathrm{mL}^{-1}$, mangiferin $14.69 \mathrm{mg} \mathrm{mL}^{-1}$, timosaponin E1 $9.56 \mathrm{mg} \mathrm{mL}^{-1}$, timosaponin E $3.15 \mathrm{mg} \mathrm{mL}^{-1}$, timosaponin B-II $40.85 \mathrm{mg} \mathrm{mL}^{-1}$, timosaponin B-III $2.32 \mathrm{mg} \mathrm{mL}^{-1}$, timosaponin A-III $11.03 \mathrm{mg} \mathrm{mL}^{-1}$, timosaponin A-I $3.26 \mathrm{mg} \mathrm{mL}^{-1}$.

\section{Components in rat plasma after oral administration}

By comparing retention time and the mass-to-charge ratio of ions with the identified components of Anemarrhena asphodeloides, eight major components were identified in rat plasma following oral administration of Rhizoma Anemarrhenae saponin extract. These were: neomangiferin, mangiferin, timosaponin E1, timosaponin E, timosaponin B-II, timosaponin B-III, timosaponin A-III and timosaponin A-I. Their molecular structures and mass ion spectra are shown in Figs. 2 and 3. They were also found in the chromatogram of the Rhizoma Anemarrhenae saponin extract in Fig. 1. A subsequent pharmacokinetic study on the eight active saponins was performed.

\section{Development and validation of HPLC-MS/MS}

Method development. - To achieve the best chromatographic separation, different mobile phase compositions, as well as flow rates, chromatographic columns and column tem- 
peratures were investigated. Finally, an acetonitrile-water system containing $0.1 \%(V / V)$ formic acid was selected as the mobile phase, as it achieved the best baseline. Better separation and peak symmetry were achieved on a Waters Xbridge $\mathrm{C}_{18}$ column $(3.5 \mathrm{~mm}, 3.0 \times$ $100 \mathrm{~mm}$ ) than with other tested columns. By comprehensively considering the retention times and separation, the column temperature was set at $30^{\circ} \mathrm{C}$.

For the pharmacokinetic study, eight saponin standards were first tested in positive and negative modes. Finally, the positive mode was chosen, as all these compounds demonstrated stronger intensity in this mode than in the negative mode. An Agilent

a)

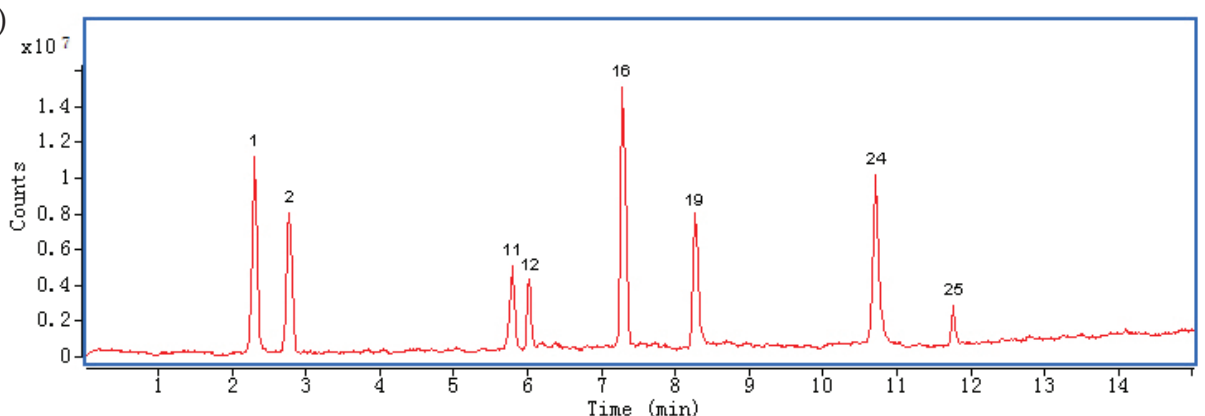

b)

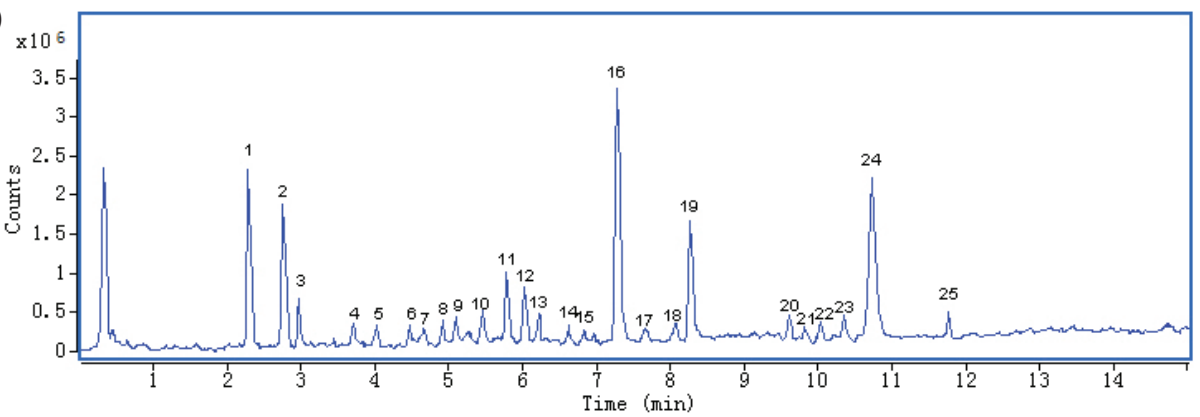

c)

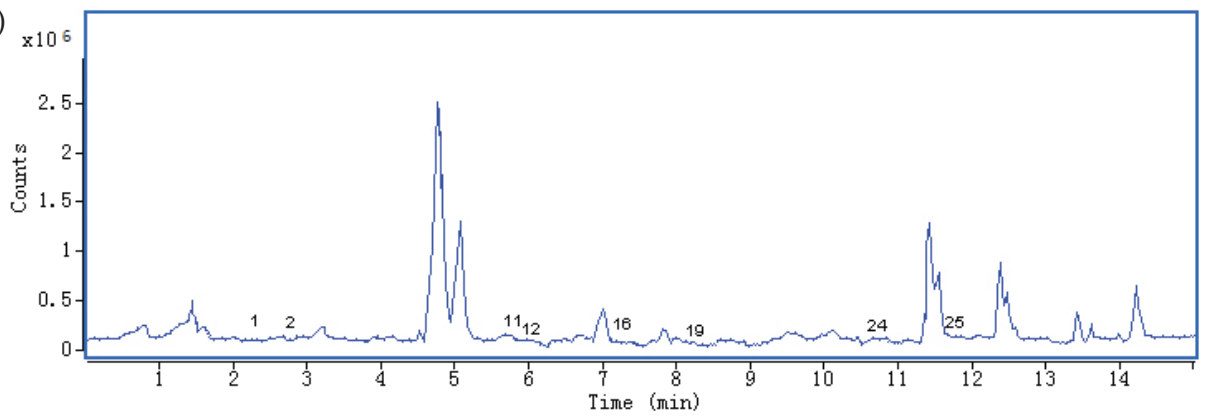

Fig. 1. HPLC-Q-TOF/MS chromatogram of 25 compounds identified in Rhizoma Anemarrhenae extract and eight saponins in rat plasma after oral administration. a) Eight saponins mixed standards; b) Rhizoma Anemarrhenae saponins extract, c) plasma sample after oral administration of Rhizoma Anemarrhenae extract. The compound names for each peak are shown in Table I. 
H.-Q. Wang et al.: Identification and pharmacokinetics of saponins in Rhizoma Anemarrhenae after oral administration to rats by HPLC-Q-TOF/MS and HPLC-MS/MS, Acta Pharm. 71 (2021) 567-585.

Table I. Components identified in Rhizoma Anemarrhenae by HPLC-Q-TOF/MS

\begin{tabular}{|c|c|c|c|c|c|c|c|}
\hline \multicolumn{2}{|c|}{ No. $t_{\mathrm{R}}(\mathrm{min}$} & \multirow{2}{*}{$\begin{array}{l}\text { Compound } \\
\text { Neomangiferin }^{\mathrm{a}}\end{array}$} & \multirow{2}{*}{$\frac{\text { Formula }}{\mathrm{C}_{25} \mathrm{H}_{28} \mathrm{O}_{16}}$} & \multirow{2}{*}{$\begin{array}{l}\text { Selected ion } \\
{[\mathrm{M}+\mathrm{H}]^{+}}\end{array}$} & \multirow{2}{*}{$\frac{\text { Expected } \mathrm{m} / \mathrm{z}}{585.1456}$} & \multirow{2}{*}{$\begin{array}{c}\text { Detected } \mathrm{m} / \mathrm{z} \\
585.1468\end{array}$} & \multirow{2}{*}{$\begin{array}{c}\text { Error (ppm) } \\
2.19\end{array}$} \\
\hline 1 & 2.32 & & & & & & \\
\hline 2 & 2.78 & Mangiferin $^{a}$ & $\mathrm{C}_{19} \mathrm{H}_{18} \mathrm{O}_{11}$ & {$[\mathrm{M}+\mathrm{H}]^{+}$} & 423.0927 & 423.0919 & -1.92 \\
\hline 3 & 2.98 & Isomangiferin & $\mathrm{C}_{19} \mathrm{H}_{18} \mathrm{O}_{11}$ & {$[\mathrm{M}+\mathrm{H}]^{+}$} & 423.0927 & 423.0931 & 0.78 \\
\hline 4 & 3.72 & Timosaponin B-V & $\mathrm{C}_{57} \mathrm{H}_{96} \mathrm{O}_{29}$ & {$[\mathrm{M}+\mathrm{H}]^{+}$} & 1245.6116 & 1245.6137 & 1.69 \\
\hline 5 & 4.04 & Timosaponin B-VI & $\mathrm{C}_{58} \mathrm{H}_{98} \mathrm{O}_{29}$ & {$[\mathrm{M}+\mathrm{H}]^{+}$} & 1259.6272 & 1259.6293 & 1.66 \\
\hline 6 & 4.48 & Timosaponin H1 & $\mathrm{C}_{56} \mathrm{H}_{92} \mathrm{O}_{28}$ & {$[\mathrm{M}+\mathrm{H}]^{+}$} & 1213.5853 & 1213.585 & -0.24 \\
\hline 7 & 4.67 & Timosaponin I1 & $\mathrm{C}_{56} \mathrm{H}_{94} \mathrm{O}_{28}$ & {$[\mathrm{M}+\mathrm{H}]^{+}$} & 1215.601 & 1215.6046 & 2.97 \\
\hline 8 & 4.49 & Timosaponin B-IV(C57) & $\mathrm{C}_{57} \mathrm{H}_{94} \mathrm{O}_{28}$ & {$[\mathrm{M}+\mathrm{H}]^{+}$} & 1227.601 & 1227.5987 & -1.87 \\
\hline 9 & 5.1 & Timosaponin I2 & $\mathrm{C}_{57} \mathrm{H}_{96} \mathrm{O}_{28}$ & {$[\mathrm{M}+\mathrm{H}]^{+}$} & 1229.6166 & 1229.6193 & 2.18 \\
\hline 10 & 5.47 & Timosaponin H2 & $\mathrm{C}_{57} \mathrm{H}_{94} \mathrm{O}_{28}$ & {$[\mathrm{M}+\mathrm{H}]^{+}$} & 1227.601 & 1227.6026 & 1.35 \\
\hline 11 & 5.79 & Timosaponin E1 ${ }^{a}$ & $\mathrm{C}_{45} \mathrm{H}_{76} \mathrm{O}_{20}$ & {$[\mathrm{M}+\mathrm{H}]^{+}$} & 937.5008 & 937.5016 & 0.83 \\
\hline 12 & 6.04 & Timosaponin $\mathrm{E}^{\mathrm{a}}$ & $\mathrm{C}_{45} \mathrm{H}_{76} \mathrm{O}_{20}$ & {$[\mathrm{M}+\mathrm{H}]^{+}$} & 937.5008 & 937.5025 & 1.78 \\
\hline 13 & 6.23 & Timosaponin N & $\mathrm{C}_{45} \mathrm{H}_{76} \mathrm{O}_{20}$ & {$[\mathrm{M}+\mathrm{H}]^{+}$} & 937.5008 & 937.5021 & 1.35 \\
\hline 14 & 6.63 & Timosaponin E2 & $\mathrm{C}_{46} \mathrm{H}_{78} \mathrm{O}_{20}$ & {$[\mathrm{M}+\mathrm{H}]^{+}$} & 951.5165 & 951.5183 & 1.96 \\
\hline 15 & 6.84 & Macrostemonoside K & $\mathrm{C}_{46} \mathrm{H}_{78} \mathrm{O}_{20}$ & {$[\mathrm{M}+\mathrm{H}]^{+}$} & 983.4885 & 983.4911 & 2.58 \\
\hline 16 & 7.29 & Timosaponin B-II & $\mathrm{C}_{45} \mathrm{H}_{76} \mathrm{O}_{19}$ & {$[\mathrm{M}+\mathrm{H}]^{+}$} & 921.5059 & 921.5066 & 0.81 \\
\hline 17 & 7.67 & Timosaponin D & $\mathrm{C}_{45} \mathrm{H}_{74} \mathrm{O}_{19}$ & {$[\mathrm{M}+\mathrm{H}]^{+}$} & 919.4903 & 919.4929 & 2.92 \\
\hline 18 & 8.07 & Timosaponin B-I & $\mathrm{C}_{46} \mathrm{H}_{78} \mathrm{O}_{19}$ & {$[\mathrm{M}+\mathrm{H}]^{+}$} & 935.5216 & 935.5227 & 1.23 \\
\hline 19 & 8.28 & Timosaponin B-III ${ }^{a}$ & $\mathrm{C}_{45} \mathrm{H}_{74} \mathrm{O}_{18}$ & {$[\mathrm{M}+\mathrm{H}]^{+}$} & 903.4953 & 903.4964 & 1.18 \\
\hline 20 & 9.62 & Timosaponin F & $\mathrm{C}_{39} \mathrm{H}_{64} \mathrm{O}_{15}$ & {$[\mathrm{M}+\mathrm{H}]^{+}$} & 773.4323 & 773.4311 & -1.61 \\
\hline 21 & 9.83 & Anemarrhenasaponin I & $\mathrm{C}_{39} \mathrm{H}_{66} \mathrm{O}_{14}$ & {$[\mathrm{M}+\mathrm{H}]^{+}$} & 759.4531 & 759.4522 & -1.21 \\
\hline 22 & 10.04 & Anemarrhenasaponin Ia & $\mathrm{C}_{40} \mathrm{H}_{68} \mathrm{O}_{14}$ & {$[\mathrm{M}+\mathrm{H}]^{+}$} & 773.4687 & 773.4703 & 2.03 \\
\hline 23 & 10.35 & Timosaponin G & $\mathrm{C}_{39} \mathrm{H}_{64} \mathrm{O}_{14}$ & {$[\mathrm{M}+\mathrm{H}]^{+}$} & 757.4374 & 757.4372 & -0.35 \\
\hline 24 & 10.74 & Timosaponin AIII & $\mathrm{C}_{39} \mathrm{H}_{64} \mathrm{O}_{13}$ & {$[\mathrm{M}+\mathrm{H}]^{+}$} & 741.4425 & 741.4431 & 0.74 \\
\hline 25 & 11.77 & Timosaponin A-I & $\mathrm{C}_{33} \mathrm{H}_{54} \mathrm{O}_{8}$ & {$[\mathrm{M}+\mathrm{H}]^{+}$} & 579.3897 & 579.389 & -1.18 \\
\hline
\end{tabular}

${ }^{a}$ Compound identified in rat plasma after oral administration.

Automatic Optimizer was used to optimize the MS/MS method to achieve the highest responses. Finally, the precursor transitions $[\mathrm{M}+\mathrm{H}]^{+}$were monitored.

Validation. - By analysing 8 different blank plasma samples, no interference of endogenous substances was observed for any of the saponins, indicating the good specificity of this method. Typical MRM chromatograms of blank plasma, blank plasma spiked with the 
a)<smiles>O=c1c2cc(OC3O[C@H](CO)[C@@H](O)[C@H](O)[C@H]3O)c(O)cc2oc2cc(O)c([C@H]3O[C@H](CO)[C@@H](O)[C@H](O)[C@H]3O)c(O)c12</smiles>

c)

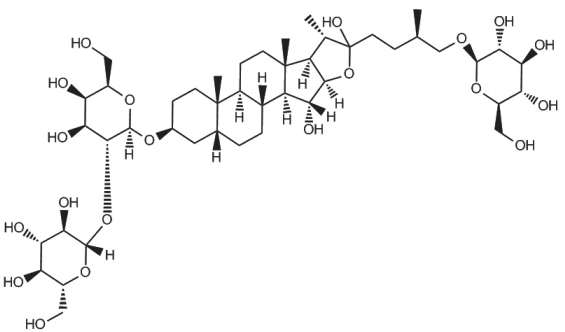

e)

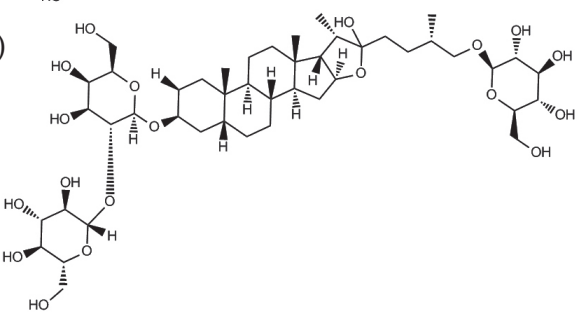

g)

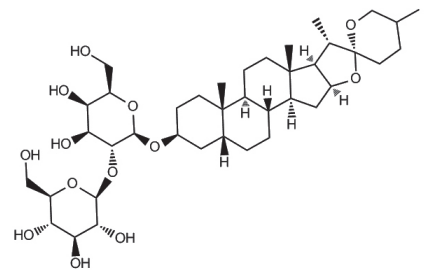

b)<smiles>O=c1c2cc(O)c(O)cc2oc2cc(O)c(C3O[C@H](CO)[C@@H](O)[C@H](O)[C@H]3O)c(O)c12</smiles>

d)

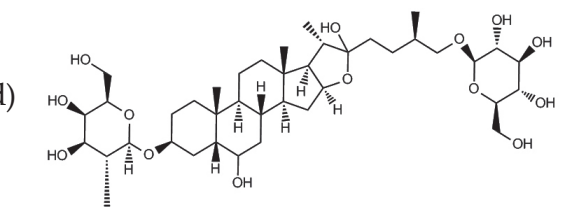

f)<smiles>CO[C@H]1O[C@H](CO)[C@@H](O)[C@H](O)[C@H]1O</smiles>

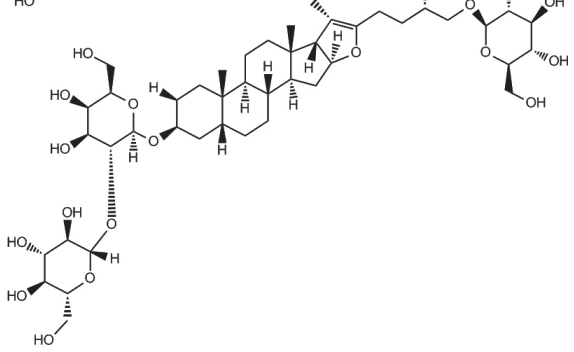

h)

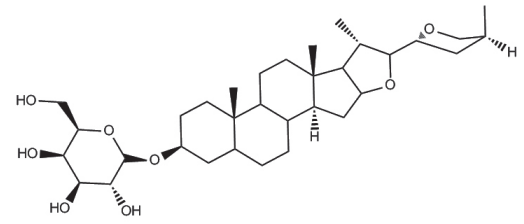

Fig. 2. Molecular structures of eight saponins detected in rat plasma: a) neomangiferin, b) mangiferin, c) timosaponin E1, d) timosaponin E, e) timosaponin B-II, f) timosaponin B-III, g) timosaponin AIII, h) timosaponin A-I.

IS and a plasma sample from a rat administered by Rhizoma Anemarrhenae saponin extract are shown in Fig. 4.

As shown in Table II, the peak area ratios of each saponin to the IS were plotted against used concentrations. The coefficient of determination $\left(R^{2}\right)$ for each of these calibration curves was higher than 0.995 , indicating a good linear detector response over the investigated ranges. The LODs of the eight saponins ranged $0.81-1.62 \mathrm{ng} \mathrm{mL}^{-1}$, while the LOQs ranged from $2.46-4.92 \mathrm{ng} \mathrm{mL}^{-1}$, which indicated good sensitivity in rat plasma.

As shown in Table III, intra- and inter-day precision values were all within 1 and $10 \%$, as well as inaccuracy values through the respective relative error. $e_{\mathrm{r}}$ for the eight saponins ranged from -9.5 to $9.0 \%$, indicating acceptable accuracy of the method. 
H.-Q. Wang et al.: Identification and pharmacokinetics of saponins in Rhizoma Anemarrhenae after oral administration to rats by HPLC-Q-TOF/MS and HPLC-MS/MS, Acta Pharm. 71 (2021) 567-585.

a)

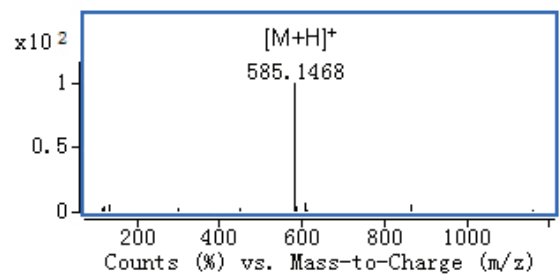

c)

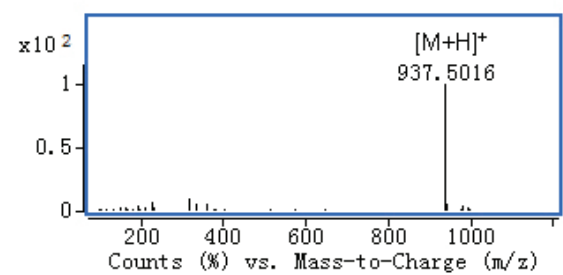

e)

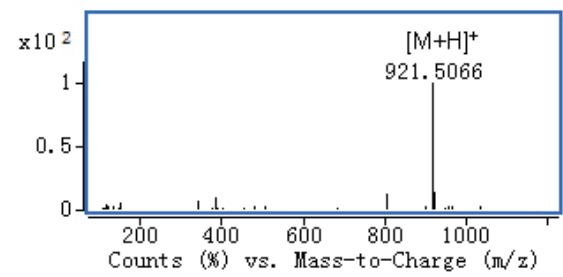

g)

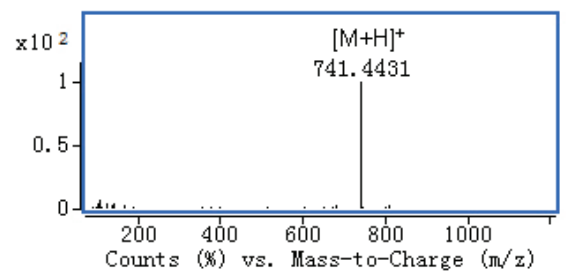

b)

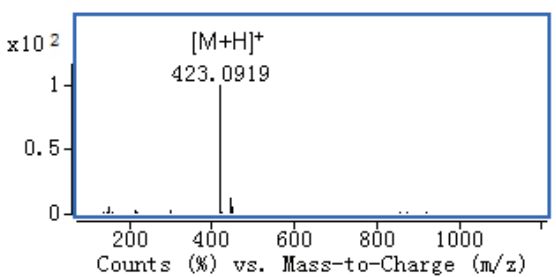

d)

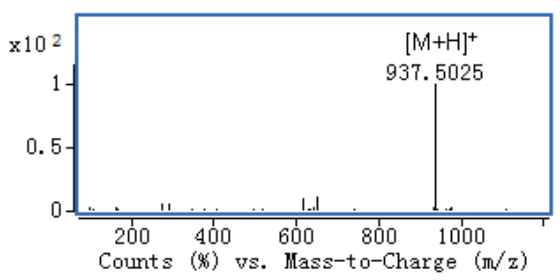

f)

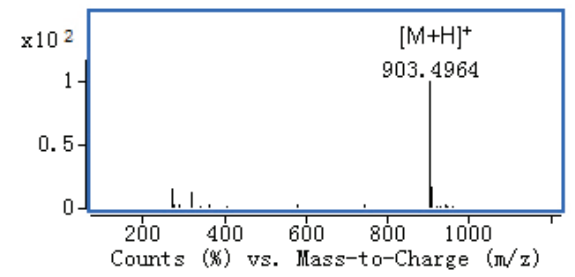

h)

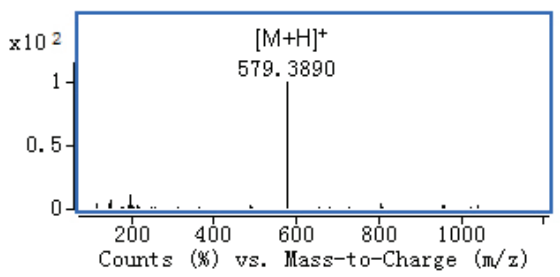

Fig. 3. Mass spectra of eight saponins: a) neomangiferin, b) mangiferin, c) timosaponin E1, d) timosaponin E, e) timosaponin B-II, f) timosaponin B-III, g) timosaponin AIII, h) timosaponin A-I.

Table IV shows that the absolute recovery for the eight saponins and IS ranged from 85.0 to $95.0 \%$, suggesting that the recoveries of the eight saponins and IS were consistent. In addition, no significant differences of extract recovery were found among the three concentrations levels of 10, 50, $250 \mathrm{ng} \mathrm{mL}^{-1}$ for timosaponin B-II and 5, 25, $100 \mathrm{ng} \mathrm{mL}^{-1}$ for the other seven saponins, indicating that the recoveries of the eight saponins and IS were not concentration-dependent. Furthermore, the matrix effect of the analytes ranged from 0 to $10 \%$.

The small deliberate changes of chromatographic conditions did not affect accuracy (recovery ranged 99.1-101.5\%), and hence the method was found robust (Table V).

The stability of saponins throughout processing and storage was comprehensively assessed for three different concentration levels, and five independent runs were performed for each concentration. The $\pm e_{\mathrm{r}}$ values for eight saponins were less than $10 \%$, indi- 
H.-Q. Wang et al.: Identification and pharmacokinetics of saponins in Rhizoma Anemarrhenae after oral administration to rats by HPLC-Q-TOF/MS and HPLC-MS/MS, Acta Pharm. 71 (2021) 567-585.

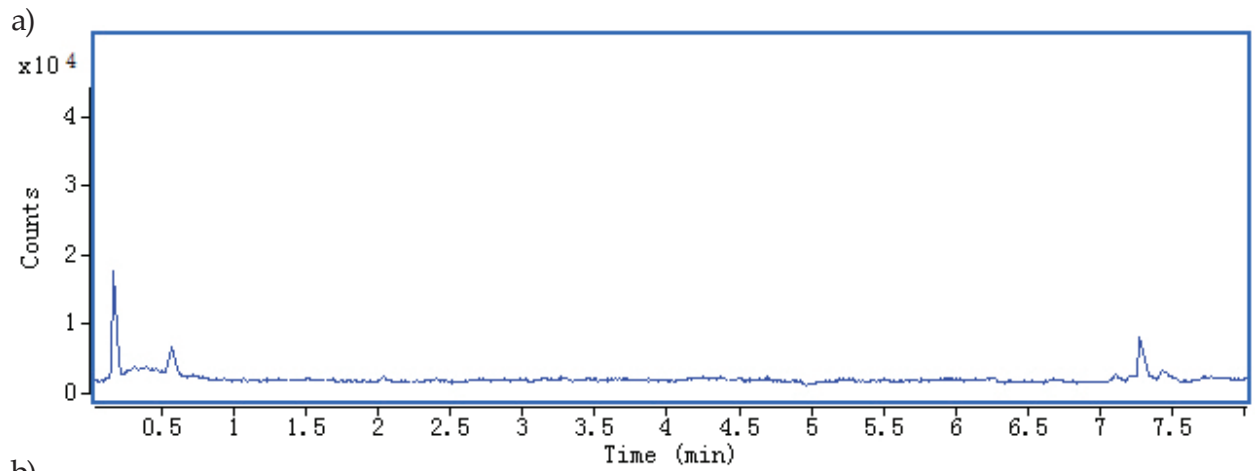

b)

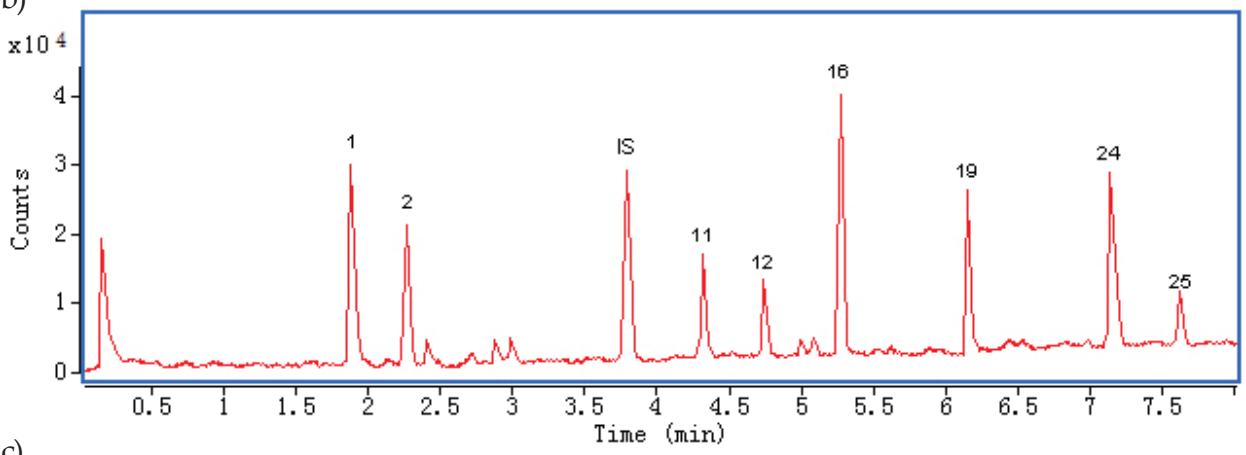

c)

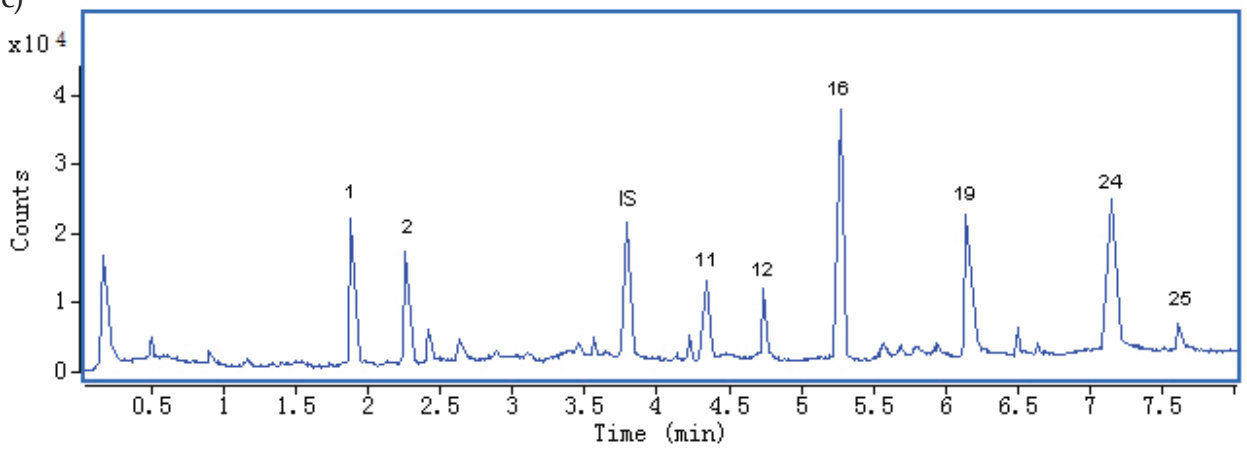

Fig. 4. HPLC-MS/MS chromatogram of eight saponins: a) blank plasma, b) eight saponins spiked in rat plasma, c) plasma sample after oral administration of Rhizoma Anemarrhenae extract. The compound names for each peak are shown in Table I.

cating that the analytes were stable in rat plasma under the following storage conditions: short-term stability at room temperature for $24 \mathrm{~h}$, long-term stability at $-40{ }^{\circ} \mathrm{C}$ for 30 days, and after three freeze-thaw cycles. All data are shown in Table VI.

The HPLC-MS/MS chromatographic parameters obtained under final conditions are summarized in Table VII. 
H.-Q. Wang et al.: Identification and pharmacokinetics of saponins in Rhizoma Anemarrhenae after oral administration to rats by HPLC-Q-TOF/MS and HPLC-MS/MS, Acta Pharm. 71 (2021) 567-585.

Table II. Regression equation and correlation coefficient $(\mathrm{R})$ for saponins in rat plasma $(\mathrm{n}=5)$

\begin{tabular}{lcccc}
\hline Analyte & $\begin{array}{c}\text { Linear range } \\
(\mathrm{ng} \mathrm{mL})\end{array}$ & Standard curve & $\mathrm{R}$ & $\begin{array}{c}\text { LOD } \\
\left(\mathrm{ng} \mathrm{mL}^{-1}\right)\end{array}$ \\
\hline Neomangiferin & $2.5-250$ & $y=2.562 x-1.268$ & 0.9963 & 0.81 \\
Mangiferin & $2.5-250$ & $y=3.051 x-1.451$ & 0.9978 & 0.84 \\
TimosaponinE1 & $2.5-250$ & $y=2.152 x-3.302$ & 0.9947 & 0.82 \\
Timosaponin E & $2.5-250$ & $y=2.145 x-3.558$ & 0.9931 & 0.83 \\
Timosaponin BII & $5-500$ & $y=2.618 x-3.049$ & 0.9949 & 1.62 \\
TimosaponinBIII & $2.5-250$ & $y=1.683 x-1.852$ & 0.9986 & 0.82 \\
TimosaponinAIII & $2.5-250$ & $y=2.017 x-3.041$ & 0.9928 & 0.81 \\
Timosaponin A-I & $2.5-250$ & $y=1.211 x-1.817$ & 0.9961 & 0.83 \\
\hline
\end{tabular}

$\mathrm{LOQ}=3 \times \mathrm{LOD}$

Table III. Intra-day and inter-day precision and accuracy for saponins in rat plasma $(\mathrm{n}=5)$

\begin{tabular}{lccccccc}
\hline \multirow{2}{*}{ Analyte } & $\begin{array}{c}\text { Expected } \\
\text { concentration } \\
\left(\mathrm{ng} \mathrm{mL} \mathrm{mL}^{-1}\right)\end{array}$ & \multicolumn{3}{c}{ Intra-day } & \multicolumn{3}{c}{ Inter-day } \\
\cline { 3 - 8 } & $\left(\mathrm{ng} \mathrm{mL}^{-1}\right)$ & $\begin{array}{c}\text { RSD } \\
(\%)\end{array}$ & $e_{\mathrm{r}}(\%)$ & $\begin{array}{c}\text { Measured } \\
\left(\mathrm{ng} \mathrm{mL}^{-1}\right)\end{array}$ & $\begin{array}{c}\text { RSD } \\
(\%)\end{array}$ & $e_{\mathrm{r}}(\%)$ \\
\hline Neomangiferin & 5.000 & 4.857 & 2.6 & -2.9 & 4.945 & 9.0 & -1.1 \\
& 25.001 & 26.609 & 9.1 & 6.4 & 26.776 & 9.8 & 7.1 \\
& 100.005 & 90.455 & 4.8 & -9.5 & 91.200 & 1.4 & -8.8 \\
Mangiferin & 5.001 & 5.220 & 6.5 & 4.4 & 4.699 & 7.4 & -6.0 \\
& 25.003 & 25.199 & 4.9 & 0.8 & 27.244 & 2.0 & 9.0 \\
Timosaponin E1 & 100.010 & 93.051 & 8.4 & -7.0 & 107.599 & 7.4 & 7.6 \\
& 5.001 & 4.779 & 2.7 & -4.4 & 4.838 & 3.1 & -3.3 \\
& 25.004 & 26.698 & 6.4 & 6.8 & 26.711 & 6.6 & 6.8 \\
Timosaponin E & 100.015 & 106.370 & 2.7 & 6.4 & 93.855 & 2.1 & -6.2 \\
& 5.000 & 4.931 & 1.4 & -1.4 & 5.147 & 6.7 & 2.9 \\
& 25.001 & 22.886 & 3.8 & -8.5 & 24.829 & 8.7 & -0.7 \\
Timosaponin B-II & 100.005 & 104.126 & 8.2 & 4.1 & 107.069 & 9.4 & 7.1 \\
& 10.001 & 9.536 & 3.0 & -4.6 & 10.447 & 2.6 & 4.5 \\
& 50.004 & 52.468 & 9.1 & 4.9 & 47.874 & 8.3 & -4.3 \\
Timosaponin B-III & 250.020 & 230.805 & 7.3 & -7.7 & 240.708 & 8.2 & -3.7 \\
& 5.002 & 4.600 & 3.7 & -8.0 & 4.944 & 9.1 & -1.2 \\
& 25.008 & 23.048 & 6.2 & -7.8 & 27.070 & 7.2 & 8.2 \\
& 100.015 & 105.203 & 5.9 & 5.2 & 103.712 & 2.6 & 3.7 \\
Timosaponin AIII & 5.003 & 5.151 & 7.2 & 3.0 & 5.030 & 2.0 & 0.6 \\
& 25.013 & 27.001 & 9.1 & 8.0 & 24.114 & 6.5 & -3.6 \\
& 100.020 & 96.621 & 4.4 & -3.4 & 106.723 & 5.0 & 6.7 \\
& 5.001 & 4.869 & 1.7 & -2.6 & 4.620 & 1.9 & -7.6 \\
& 25.005 & 25.885 & 5.8 & 3.5 & 24.054 & 9.7 & -3.8 \\
& 100.025 & 105.242 & 2.8 & 5.2 & 103.962 & 6.1 & 3.9 \\
\hline
\end{tabular}


H.-Q. Wang et al.: Identification and pharmacokinetics of saponins in Rhizoma Anemarrhenae after oral administration to rats by HPLC-Q-TOF/MS and HPLC-MS/MS, Acta Pharm. 71 (2021) 567-585.

Table IV. Matrix effect and extraction recovery of saponins and IS in rat plasma $(\mathrm{n}=5)$

\begin{tabular}{lccccc}
\hline \multirow{2}{*}{ Analyte } & $\begin{array}{c}\text { Concentration } \\
\left(\mathrm{ng} \mathrm{mL} \mathrm{m}^{-1}\right)\end{array}$ & \multicolumn{2}{c}{ Matrix effect } & \multicolumn{2}{c}{ Extraction recovery } \\
\cline { 3 - 6 } Neomangiferin & 5.000 & 4.2 & 2.9 & 88.1 & RSD $(\%)$ \\
\hline \multirow{4}{*}{ Mangiferin } & 25.001 & 3.1 & 3.2 & 94.9 & 4.5 \\
& 100.005 & 1.7 & 7.4 & 92.0 & 5.2 \\
& 5.001 & 5.7 & 3.3 & 91.7 & 2.4 \\
Timosaponin E1 & 25.003 & 5.4 & 2.2 & 94.6 & 5.4 \\
& 100.010 & 2.9 & 7.4 & 94.8 & 6.6 \\
Timosaponin E & 5.001 & 7.6 & 5.0 & 85.2 & 2.0 \\
& 25.004 & 9.0 & 6.2 & 90.2 & 6.2 \\
& 100.015 & 7.6 & 2.1 & 92.6 & 1.5 \\
Timosaponin B-II & 5.000 & 3.1 & 1.3 & 86.6 & 1.4 \\
& 25.001 & 1.8 & 7.4 & 94.0 & 4.5 \\
Timosaponin B-III & 100.005 & 0.8 & 1.9 & 89.2 & 5.6 \\
& 10.001 & 7.2 & 9.7 & 87.5 & 8.4 \\
& 50.004 & 4.8 & 7.7 & 92.1 & 2.5 \\
Timosaponin AIII & 250.020 & 4.2 & 2.0 & 85.3 & 9.3 \\
& 5.002 & 6.9 & 3.3 & 87.2 & 6.2 \\
Timosaponin A-I & 25.008 & 8.2 & 6.6 & 92.7 & 6.2 \\
& 100.015 & 9.5 & 3.0 & 93.4 & 7.4 \\
Internal standard & 5.003 & 7.1 & 9.7 & 90.2 & 6.1 \\
\hline & 25.013 & 1.9 & 8.0 & 94.3 & 6.3 \\
& 100.020 & 0.4 & 1.7 & 85.5 & 7.5 \\
& 5.001 & 3.1 & 2.5 & 85.2 & 6.9 \\
& 25.005 & 4.8 & 2.4 & 94.8 & 1.5 \\
& 100.025 & 1.2 & 9.2 & 88.4 & 4.1 \\
& 60.002 & 4.2 & 2.9 & 88.1 & 5.4 \\
\hline
\end{tabular}

Table V. Method robustness for saponins in rat plasma

\begin{tabular}{|c|c|c|c|c|c|c|c|c|}
\hline \multirow[b]{2}{*}{$\begin{array}{l}\text { Chromatographic } \\
\text { conditions }\end{array}$} & \multicolumn{8}{|c|}{ Recovery (\%) } \\
\hline & $\begin{array}{l}\text { Neo- } \\
\text { mangi- } \\
\text { ferin }\end{array}$ & $\begin{array}{l}\text { Mangi- } \\
\text { ferin }\end{array}$ & $\begin{array}{c}\text { Timosa- } \\
\text { ponin } \\
\text { E1 }\end{array}$ & $\begin{array}{c}\text { Timosa- } \\
\text { ponin } \\
\text { E }\end{array}$ & $\begin{array}{c}\text { Timosa- } \\
\text { ponin } \\
\text { BII }\end{array}$ & $\begin{array}{c}\text { Timosa- } \\
\text { ponin } \\
\text { BIII }\end{array}$ & $\begin{array}{c}\text { Timosa- } \\
\text { ponin } \\
\text { AIII }\end{array}$ & $\begin{array}{c}\text { Timosa- } \\
\text { ponin } \\
\text { A-I } \\
\end{array}$ \\
\hline \multicolumn{9}{|c|}{ Mobile phase flow rate } \\
\hline $0.3 \mathrm{~mL} \mathrm{~min}^{-1}$ & 100.9 & 99.4 & 100.1 & 100.4 & 100.3 & 99.5 & 100.9 & 99.4 \\
\hline $0.5 \mathrm{~mL} \mathrm{~min}^{-1}$ & 100.8 & 100 & 99.1 & 100.1 & 101.1 & 100.3 & 100.8 & 100.0 \\
\hline \multicolumn{9}{|c|}{ Column temperature } \\
\hline $28^{\circ} \mathrm{C}$ & 100.7 & 101.0 & 99.1 & 100.6 & 99.5 & 100.5 & 100.7 & 101.0 \\
\hline $32{ }^{\circ} \mathrm{C}$ & 99.1 & 100.9 & 99.5 & 101.4 & 99.7 & 100.8 & 99.1 & 100.9 \\
\hline \multicolumn{9}{|c|}{ Drying gas temperature } \\
\hline $340^{\circ} \mathrm{C}$ & 100.9 & 101.5 & 100.3 & 99.3 & 99.1 & 99.6 & 100.9 & 101.5 \\
\hline $360^{\circ} \mathrm{C}$ & 101.2 & 99.5 & 100.7 & 99.8 & 100.4 & 101.5 & 101.2 & 99.5 \\
\hline \multicolumn{9}{|l|}{ Drying gas flow rate } \\
\hline $9 \mathrm{~L} \mathrm{~min}^{-1}$ & 100.7 & 101.0 & 99.1 & 100.6 & 99.5 & 100.5 & 100.7 & 101.0 \\
\hline $11 \mathrm{~L} \mathrm{~min}^{-1}$ & 99.1 & 100.9 & 99.5 & 101.4 & 99.7 & 100.8 & 99.1 & 100.9 \\
\hline
\end{tabular}


H.-Q. Wang et al.: Identification and pharmacokinetics of saponins in Rhizoma Anemarrhenae after oral administration to rats by HPLC-Q-TOF/MS and HPLC-MS/MS, Acta Pharm. 71 (2021) 567-585.

Table VI. Stability of eight saponins in rat plasma $(\mathrm{n}=5)$

\begin{tabular}{|c|c|c|c|c|c|c|c|}
\hline \multirow{2}{*}{ Analytes } & \multirow{2}{*}{$\begin{array}{l}\text { Concen- } \\
\text { tration } \\
\left(\mathrm{ng} \mathrm{mL} L^{-1}\right)\end{array}$} & \multicolumn{2}{|c|}{$\begin{array}{l}\text { Frozen at }-40^{\circ} \mathrm{C} \\
\quad \text { for } 30 \text { days }\end{array}$} & \multicolumn{2}{|c|}{$\begin{array}{c}\text { Room temperature } \\
\text { for } 24 \mathrm{~h}\end{array}$} & \multicolumn{2}{|c|}{$\begin{array}{c}\text { Freeze-thaw } \\
\text { cycles }(3 x)\end{array}$} \\
\hline & & $\begin{array}{l}\text { Measured } \\
\left(\text { ng mL } \mathrm{mL}^{-1}\right)\end{array}$ & $e_{\mathrm{r}}(\%)$ & $\begin{array}{l}\text { Measured } \\
\left(\text { ng mL }^{-1}\right)\end{array}$ & $e_{\mathrm{r}}(\%)$ & $\begin{array}{l}\text { Measured } \\
\left(\text { ng mL } L^{-1}\right)\end{array}$ & $e_{\mathrm{r}}(\%)$ \\
\hline \multirow{3}{*}{ Neomangiferin } & 5.000 & 4.824 & -3.5 & 4.674 & -6.5 & 5.263 & 5.3 \\
\hline & 25.001 & 24.395 & -2.4 & 26.041 & 4.2 & 23.200 & -7.2 \\
\hline & 100.005 & 106.791 & 6.8 & 98.045 & -2.0 & 90.464 & -9.5 \\
\hline \multirow{3}{*}{ Mangiferin } & 5.001 & 5.471 & 9.4 & 4.571 & -8.6 & 5.378 & 7.6 \\
\hline & 25.003 & 24.557 & -1.8 & 25.387 & 1.5 & 23.014 & -8.0 \\
\hline & 100.010 & 106.742 & 6.7 & 102.267 & 2.3 & 109.088 & 9.1 \\
\hline \multirow[t]{3}{*}{ Timosaponin E1 } & 5.001 & 4.792 & -4.2 & 4.852 & -3.0 & 5.353 & 7.0 \\
\hline & 25.004 & 23.300 & -6.8 & 26.745 & 7.0 & 23.876 & -4.5 \\
\hline & 100.015 & 93.866 & -6.1 & 98.127 & -1.9 & 100.946 & 0.9 \\
\hline \multirow[t]{3}{*}{ Timosaponin E } & 5.000 & 5.363 & 7.3 & 5.384 & 7.7 & 4.676 & -6.5 \\
\hline & 25.001 & 25.210 & 0.8 & 23.333 & -6.7 & 27.034 & 8.1 \\
\hline & 100.005 & 97.655 & -2.3 & 94.291 & -5.7 & 107.734 & 7.7 \\
\hline \multirow[t]{3}{*}{ Timosaponin B-II } & 10.001 & 10.290 & 2.9 & 9.368 & -6.3 & 9.262 & -7.4 \\
\hline & 50.004 & 49.209 & -1.6 & 51.374 & 2.7 & 47.028 & -6.0 \\
\hline & 250.020 & 253.615 & 1.4 & 227.978 & -8.8 & 266.853 & 6.7 \\
\hline \multirow[t]{3}{*}{ Timosaponin B-III } & 5.002 & 4.678 & -6.5 & 5.474 & 9.4 & 4.622 & -7.6 \\
\hline & 25.008 & 26.937 & 7.7 & 25.378 & 1.5 & 25.692 & 2.7 \\
\hline & 100.015 & 102.201 & 2.2 & 104.269 & 4.3 & 99.680 & -0.3 \\
\hline \multirow[t]{3}{*}{ Timosaponin AIII } & 5.003 & 4.998 & -0.1 & 4.789 & -4.3 & 4.674 & -6.6 \\
\hline & 25.013 & 25.257 & 1.0 & 26.039 & 4.1 & 25.338 & 1.3 \\
\hline & 100.020 & 95.411 & -4.6 & 91.862 & -8.2 & 90.821 & -9.2 \\
\hline \multirow[t]{3}{*}{ Timosaponin A-I } & 5.001 & 4.529 & -9.4 & 4.598 & -8.1 & 4.520 & -9.6 \\
\hline & 25.005 & 26.859 & 7.4 & 25.488 & 1.9 & 22.996 & -8.0 \\
\hline & 100.025 & 103.335 & 3.3 & 90.883 & -9.1 & 107.383 & 7.4 \\
\hline
\end{tabular}

Pharmacokinetic study after intragastric administration of Rhizoma Anemarrhenae saponin extract

Since eight saponins were detected in rat plasma after oral administration of Rhizoma Anemarrhenae saponin extract, their pharmacokinetic profiles in vivo were further investigated by the use of the HPLC-MS/MS method. The pharmacokinetic profile of timosaponin AIII was determined up to $48 \mathrm{~h}$ after oral administration, whereas timosaponin $\mathrm{E}^{\prime}$ profile was determined up to $24 \mathrm{~h}$ due to the drop of the plasma concentration below LOQ $24 \mathrm{~h}$ after oral administration. The other six saponins were all determined up to $36 \mathrm{~h}$ after oral administration. The mean plasma concentrations in the concentration-time curves are shown in Fig. 5. The mean pharmacokinetic parameter values were calculated by using DAS 3.0 based on the non-compartmental pharmacokinetic model and are summarized in Table VIII.

As shown in Fig. 5 and Table VIII, $T_{\max }$ values of the eight saponins ranged from 2 to $8 \mathrm{~h}$, with timosaponin E1 with the lowest $\left(T_{\max } 2.12 \mathrm{~h}\right)$ and timosaponin AIII the highest 


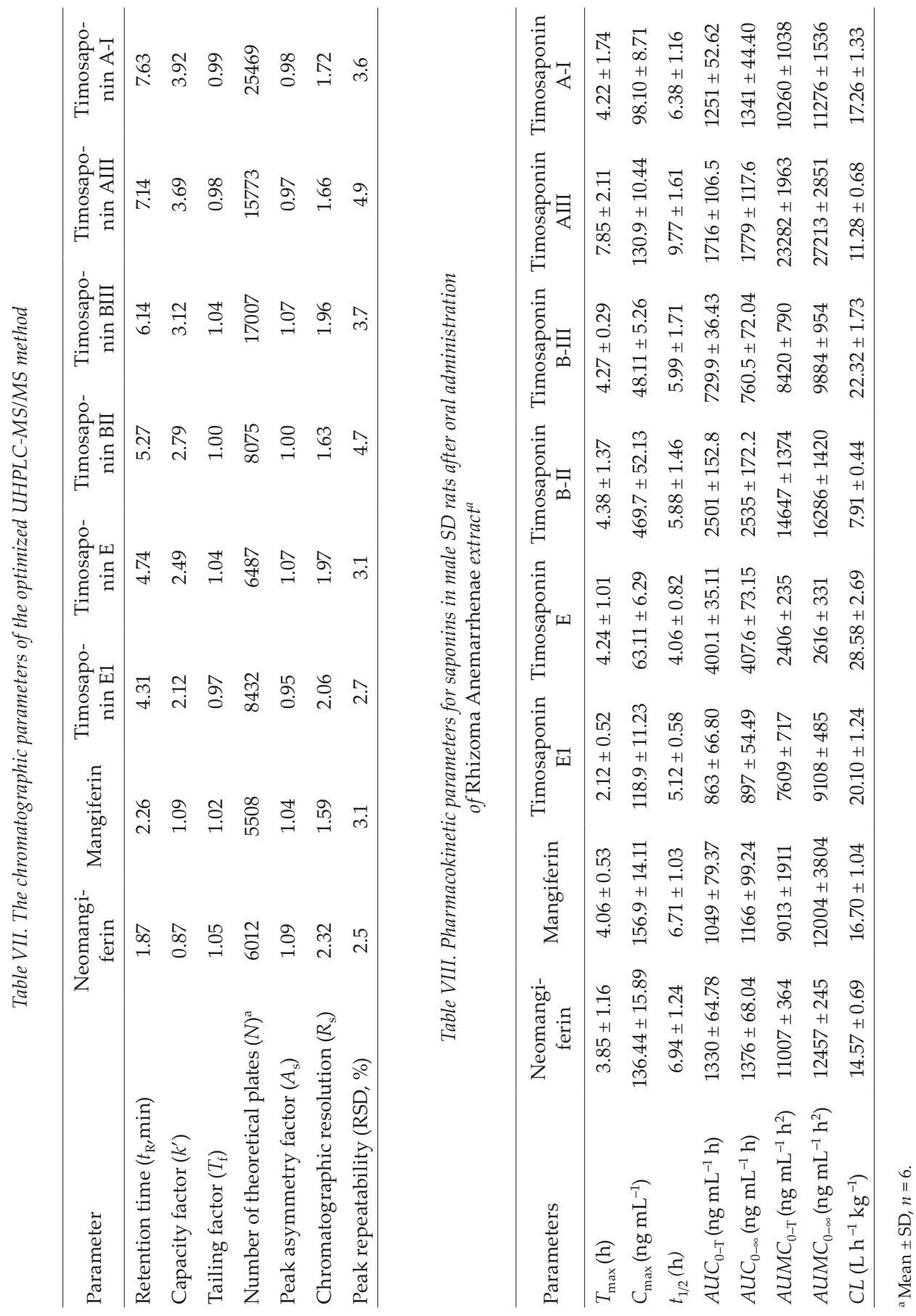


a)

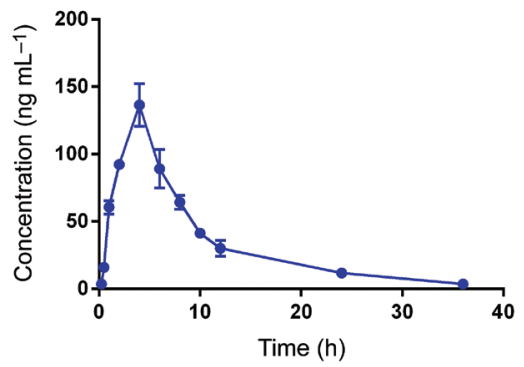

c)

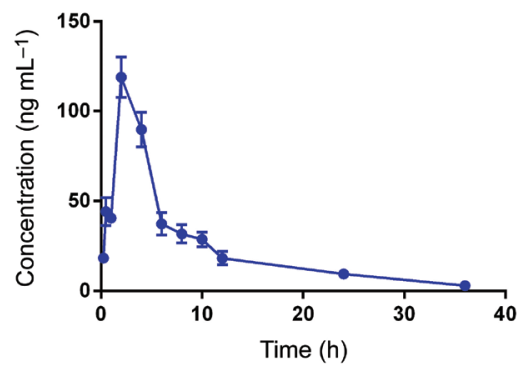

e)

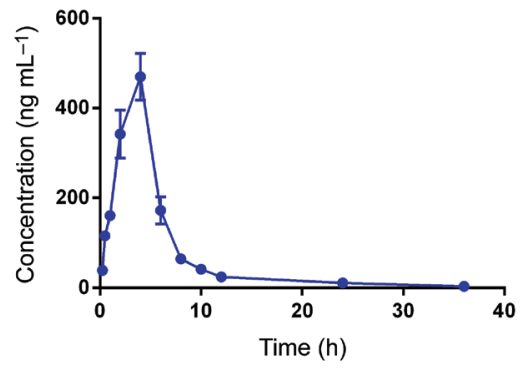

g)

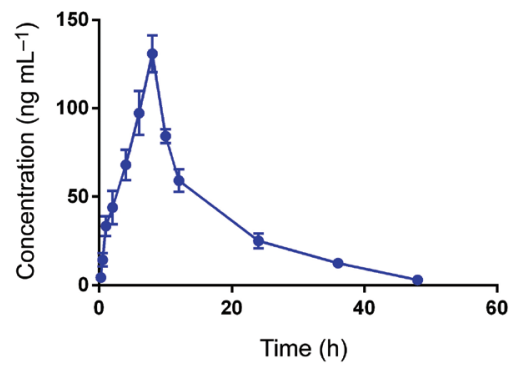

b)

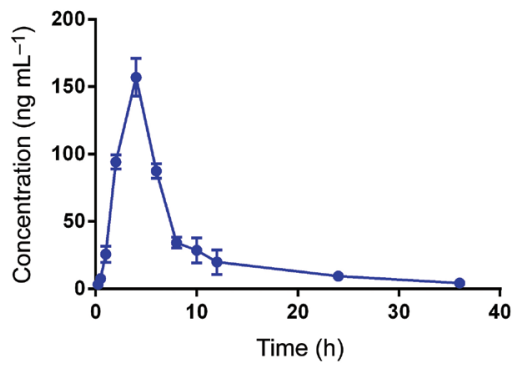

d)

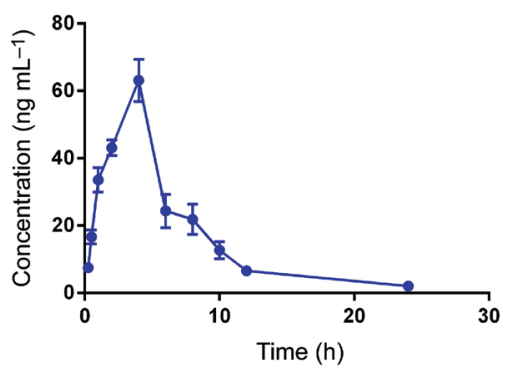

f)

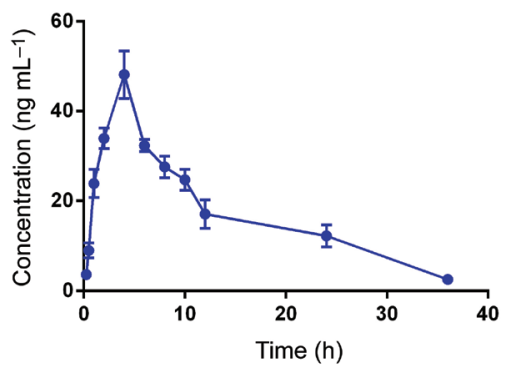

h)

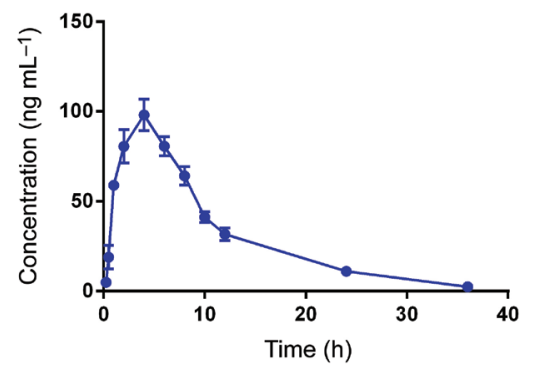

Fig. 5. Plasma concentration-time curves of eight saponins in rats after oral administration of Rhizoma Anemarrhenae saponin extract: a) neomangiferin, b) mangiferin, c) timosaponin E1, d) timosaponin E, e) timosaponin B-II, f) timosaponin B-III, g) timosaponin AIII, h) timosaponin A-I. Mean \pm SD, $n=6$. 
H.-Q. Wang et al.: Identification and pharmacokinetics of saponins in Rhizoma Anemarrhenae after oral administration to rats by HPLC-Q-TOF/MS and HPLC-MS/MS, Acta Pharm. 71 (2021) 567-585.

$\left(T_{\max } 7.85 \mathrm{~h}\right)$ value. The $T_{\max }$ values of the other six saponins were approximately $4 \mathrm{~h}$. The elimination half-life $\left(t_{1 / 2}\right)$ of the eight saponins ranged from 4.06 to $9.77 \mathrm{~h}$, with timosaponin AIII showing the highest value $(9.77 \mathrm{~h})$, indicating a relatively long body residence time and slow excretion. The plasma concentrations of the eight saponins were very low, even for timosaponin B-II which dominated in the Rhizoma Anemarrhenae saponin extract, indicating a relatively low oral bioavailability for these saponins.

\section{CONCLUSIONS}

In this paper, 25 compounds were identified in raw Rhizoma Anemarrhenae extract, and eight saponins were further detected in rat plasma after oral administration of the extract by HPLC-Q-TOF/MS. Then, a sensitive, specific and accurate HPLC-MS/MS method was developed, validated and effectively employed in quantitative analysis of eight saponins in the extract (neomangiferin, mangiferin, timosaponin, timosaponin, timosaponin B-II, timosaponin B-III, timosaponin A-III and timosaponin A-I) and in their pharmacokinetic study after oral administration to rats.

Pharmacokinetic parameter, $T_{\max }$ of the eight saponins ranged from 2 to $8 \mathrm{~h}$; elimination half-life $\left(t_{1 / 2}\right)$ ranged from 4 to $10 \mathrm{~h}$, indicating slow excretion. Concentrations of the saponins in plasma were all very low, indicating a relatively low oral bioavailability.

This is the first systematic study investigating the pharmacokinetic characteristics of Rhizoma Anemarrhenae saponins, therefore, we believe that the results from this research could provide meaningful guidance for future clinical research in pharmacodynamics, pharmacology and toxicology of this plant.

Acknowledgements. - This study was financially supported by the National Military Medical Innovation Project (16CXZ012) and the Traditional Chinese Medicine Inheritance and Scientific and Technological Innovation Project of Shanghai Municipal Health Commission (ZYCC2019025).

\section{REFERENCES}

1. Y. J. Kang, H. J. Chung, J. W. Nam, H. J. Park, E. K. Seo, Y. S. Kim, D. Lee and S. K. Lee, Cytotoxic and antineoplastic activity of timosaponin A-III for human colon cancer cells, J. Nat. Prod. 74 (2011) 701-706; https://doi.org/10.1021/np1007735

2. S. Y. Park, Y. H. Choi and W. Lee, Dangnyohwan improves glucose utilization and reduces insulin resistance by increasing the adipocyte-specific GLUT4 expression in Otsuka Long-Evans Tokushima Fatty rats, J. Ethnopharmacol. 115 (2008) 473-482; https://doi.org/10.1016/j.jep.2007.10.040

3. T. Liu, X. N. An, D. L. Liu and Y. J. Wei, A comparison of several second-order algorithms for simultaneous determination of neomangiferin and mangiferin with severe spectral overlapping in Anemarrhenae rhizoma, Spectrochim. Acta A 208 (2019) 172-178; https://doi.org/10.1016/j.saa.2018.09.057

4. K.-Y. Ji, K. M. Kim, Y. H. Kim, A-R. Im, J. Y. Lee, B. Park, M. Na and S. Chae, The enhancing immune response and anti-inflammatory effects of Anemarrhena asphodeloides extract in RAW 264.7 cells, Phytomedicine 59 (2019) Article ID 152789; https://doi.org/10.1016/j.phymed.2018.12.012

5. Y. Wang, Y. Dan, D. Yang, Y. Hu, L. Zhang, C. Zhang, H. Zhu, Z. Cui, M. Li and Y. Liu, The genus Anemarrhena bunge: A review on ethnopharmacology, phytochemistry and pharmacology, J. Ethnopharmacol. 153 (2014) 42-60; https://doi.org/10.1016/j.jep.2014.02.013 
H.-Q. Wang et al.: Identification and pharmacokinetics of saponins in Rhizoma Anemarrhenae after oral administration to rats by HPLC-Q-TOF/MS and HPLC-MS/MS, Acta Pharm. 71 (2021) 567-585.

6. Z. Y. Meng, J. Y. Zhang, S. X. Xu and K. Sugahara, Steroidal saponins from Anemarrhena asphodeloides and their effects on superoxide generation, Planta Med. 65 (1999) 661-663; https://doi. org/10.1055/s-2006-960842

7. J. Zhang, Z. Meng, M. Zhang, D. Ma, S. Xu and H. Kodama, Effect of six steroidal saponins isolated from anemarrhenae rhizoma on platelet aggregation and hemolysis in human blood, Clin. Chim. Acta 289 (1999) 79-88; https://doi.org/10.1016/s0009-8981(99)00160-6

8. Z. Tang, G. Li, J. Yang, J. Duan, D. Qian, J. Guo, Z. Zhu and Z. Song, Anemarrhena asphodeloides non-steroidal saponin components alter the pharmacokinetic profile of its steroidal saponins in rat, Molecules 20 (2015) 11777-11792; https://doi.org/10.3390/molecules200711777

9. Y. Wang, J. Xu and H. Qu, Structure characterization and identification steroidal saponins from Ophiopogon japonicus Ker-Gawler (Liliaceae) by high-performance liquid chromatography with ion trap mass spectrometry, Phytochem. Anal 22 (2011) 166-171; https://doi.org/10.1002/pca.1263

10. B.-Y. Yang, J. Zhang, Y. Liu and H.-X. Kuang, Steroidal saponins from the rhizomes of Anemarrhena asphodeloides, Molecules 21 (2016) Article ID 1075 (9 pages); https://doi.org/10.3390/molecules 21081075

11. N. Kaname, J. Zhang, Z. Meng, S. Xu, K. Sugahara, Y. Doi and H. Kodama, Effect of timosaponin E1 and E2 on superoxide generation induced by various stimuli in human neutrophils and on platelet aggregation in human blood, Clin. Chim. Acta 295 (2000) 129-140; https://doi.org/10.1016/ s0009-8981(00)00196-0

12. X. Zhao, C. Liu, Y. Qi, L. Fang, J. Luo, K. Bi and Y. Jia, Timosaponin B-II ameliorates scopolamineinduced cognition deficits by attenuating acetylcholinesterase activity and brain oxidative damage in mice, Metab. Brain Dis. 31 (2016) 1455-1461; https://doi.org/10.1007/s11011-016-9877-z

13. B. Lee, K. Jung and D. H. Kim, Timosaponin AIII, a saponin isolated from Anemarrhena asphodeloides, ameliorates learning and memory deficits in mice, Pharmacol. Biochem. Behav. 93 (2009) 121-127; https://doi.org/10.1016/j.pbb.2009.04.021

14. B. R. Kim, Y. C. Cho, H. T. T. Le, H. L. Vuong, S. Lee and S. Cho, Suppression of inflammation by the rhizome of Anemarrhena asphodeloides via regulation of nuclear factor-kappaB and p38 signal transduction pathways in macrophages, Biomed. Rep. 6 (2017) 691-697; https://doi.org/10.3892/ br.2017.895

15. J. Y. Kim, J. S. Shin, J. H. Ryu, S. Y. Kim, Y. W. Cho, J. H. Choi and K. T. Lee, Anti-inflammatory effect of anemarsaponin B isolated from the rhizomes of Anemarrhena asphodeloides in LPS-induced RAW 264.7 macrophages is mediated by negative regulation of the nuclear factor-kappaB and p38 pathways, Food Chem. Toxicol. 47 (2009) 1610-1617; https://doi.org/10.1016/j. fct.2009.04.009

16. W. Q. Lu, Y. Qiu, T. J. Li, X. Tao, L. N. Sun and W. S. Chen, Timosaponin B-II inhibits pro-inflammatory cytokine induction by lipopolysaccharide in BV2 cells, Arch. Pharm. Res. 32 (2009) 13011308; https://doi.org/10.1007/s12272-009-1916-4

17. W. Zhao, M. Wang, L. Shao, M. Liao, K. Liu, F. Huang and B. Liu, The total phenolic fraction of Anemarrhena asphodeloides inhibits inflammation and reduces insulin resistance in adipocytes via regulation of AMP-kinase activity, Planta Med.80(2014) 146-152; https://doi.org/10.1055/s-0033-1360197

18. H. Nian, L. P. Qin, W. S. Chen, Q. Y. Zhang, H. C. Zheng and Y. Wang, Protective effect of steroidal saponins from rhizome of Anemarrhena asphodeloides on ovariectomy-induced bone loss in rats, Acta Pharmacol. Sin. 27 (2006) 728-734; https://doi.org/10.1111/j.1745-7254.2006.00328.x

19. G. J. Wang, L. C. Lin, C. F. Chen, J. S. Cheng, Y. K. Lo, K. J. Chou, K. C. Lee, C. P. Liu, Y. Y. Wu, W. $\mathrm{Su}$, W. C. Chen and C. R. Jan, Effect of timosaponin A-III, from Anemarrhenae asphodeloides Bunge (Liliaceae), on calcium mobilization in vascular endothelial and smooth muscle cells and on vascular tension, Life Sci. 71 (2002) 1081-1090; https://doi.org/10.1016/s0024-3205(02)01794-0 
H.-Q. Wang et al.: Identification and pharmacokinetics of saponins in Rhizoma Anemarrhenae after oral administration to rats by HPLC-Q-TOF/MS and HPLC-MS/MS, Acta Pharm. 71 (2021) 567-585.

20. Y. Feng, B. Chen, A. Lin and Y. Liu, Simultaneous determination of timosaponin B-II and A-III in rat plasma by LC-MS/MS and its application to pharmacokinetic study, J. Chromatogr. B 965 (2014) 119-126; https://doi.org/10.1016/j.jchromb.2014.06.017

21. Z. Liu, X. Dong, X. Ding, X. Chen, L. Lv, Y. Li and Y. Chai, Comparative pharmacokinetics of timosaponin B-II and timosaponin A-III after oral administration of Zhimu-Baihe herb-pair, Zhimu extract, free timosaponin B-II and free timosaponin A-III to rats, J. Chromatogr. B 926 (2013) 28-35; https://doi.org/10.1016/j.jchromb.2013.03.003

22. X. Tian, Z. Xu, Z. Li, Y. Ma, S. Lian, X. Guo, P. Hu, Y. Gao and C. Huang, Pharmacokinetics of mangiferin and its metabolite-norathyriol, Part 2: Influence of UGT, CYP450, P-gp, and enterobacteria and the potential interaction in Rhizoma Anemarrhenae decoction with timosaponin B2 as the major contributor, BioFactors 42 (2016) 545-555; https://doi.org/10.1002/biof.1290

23. F. Cai, L. Sun, S. Gao, Y. Yang, Q. Yang and W. Chen, A rapid and sensitive liquid chromatographytandem mass spectrometric method for the determination of timosaponin B-II in blood plasma and a study of the pharmacokinetics of saponin in the rat, J. Pharm. Biomed. Anal. 48 (2008) 14111416; https://doi.org/10.1016/j.jpba.2008.09.032

24. L. Lai, L. C. Lin, J. H. Lin and T. H. Tsai, Pharmacokinetic study of free mangiferin in rats by microdialysis coupled with microbore high-performance liquid chromatography and tandem mass spectrometry, J. Chromatogr. A 987 (2003) 367-374; https://doi.org/10.1016/s0021-9673(02)01415-2

25. B. Wang, H. Zhang, X. Dong, L. Lv , L. Zhao, Z. Lou, Y. Chai and G. Zhang, Separation and characterization of steroidal saponins in Paris pllyphylla by high-performance liquid chromatography coupled with time-of-flight mass spectrometry and ion trap mass spectrometry, J. Liq. Chromatogr. Relat. Technol. 36 (2013) 1661-1677; https://doi.org/10.1080/10826076.2012.695313

26. International Conference on Harmonisation of Technical Requirements for Registration of Pharmaceuticals for Human Use, ICH Harmonised Tripartite Guideline, Validation of Analytical Procedures: Text and Methodology, Q2 (R1), Current Step 4 version, November 2005; https://www.ich.org/fileadmin/Public_Web_Site/ICH_Products/Guidelines/Quality/Q2_R1/Step 4/Q2_R1_Guideline.pdf; last access date March 10, 2018.

27. Z. Liu, D. Zhu, Y. Qi, X. Chen, Z. Zhu and Y. Chai, Elucidation of steroid glycosides in Anemarrhena asphodeloides extract by means of comprehensive two-dimensional reversed-phase/polyamine chromatography with mass spectrometric detection, J. Sep. Sci. 35 (2012) 2210-2218; https://doi. org/10.1002/jssc.201200236 